\title{
PODER NO EGITO PTOLOMAICO: UMA ABORDAGEM MÁGICO-RELIGIOSA DA LEGITIMIDADE
}

Julio Gralha ${ }^{1}$

\begin{abstract}
Resumo
Este artigo tem por objetivo apresentar estratégias que permitiram a dinastia ptolomaica estabelecer sua legitimidade por quase três séculos. De fato, defendo que um projeto político-religioso, que tinha por foco a adoção de práticas mágico-religiosas egípcias e da monarquia divina foi levado a efeito pela realeza ptolomaica. Nesta pesquisa cito como exemplo quatro estratégias: A legitimidade ptolomaica pela deificação, pela fundação de cidade, pela titulação e pela construção de templos. Defendo também que o desenvolvimento de um programa de construção de templos no Alto Egito, principalmente após a Rebelião Tebana, foi capaz de estabelecer a cooperação e a cooptação da elite e segmentos sociais locais consolidando a legitimidade dinástica. Além disso, defendo que a egipcianização da realeza ptolomaica é mais profunda do que a historiografia ressalta se comparada a helenização.
\end{abstract}

\section{Palavras chave}

Dinastina Ptolomaica 305-30 b.C.; Egiptologia; História Antiga; Relações de Poder.

\footnotetext{
1 Professor Doutor, Universidade Federal Fluminense, Campos, Brasil. email: julio.egito@gmail.com
} 


\begin{abstract}
This paper aims to present strategies that allowed the Ptolemaic dynasty to establish its legitimacy for almost three centuries. In fact, I argue that a political-religious project that focused on the adoption of Egyptian magical-religious practices and the divine monarchy was carried out by Ptolemaic royalty. In this research I cite as an example four strategies: Ptolemaic legitimacy by means of deification, by means of foundation of a city, by means of royal titles and, by means of building of temples. I also argue that the development of a temple-building program in Upper Egypt, especially after the Theban Rebellion, was able to establish cooperation and co-optation of the elite and local social segments, consolidating dynastic legitimacy. Moreover, I argue that the Egyptianization of Ptolemaic royalty is deeper than historiography stands out compared to Hellenization.
\end{abstract}

\title{
Keywords
}

Ptolemaic dynasty, 305-30 B.C.; Egyptology; Ancient History; Power Relation. 
Ao contrário de alguns autores que defendem a pouca interação entre as culturas egípcia e greco-macedônia, a forma como a legitimidade da dinastia ptolomaica foi empreendida nos permite verificar que tal interação foi muito mais profunda do que se possa pensar, e provavelmente sem tal abordagem seria difícil a manutenção desta dinastia estrangeira por quase três séculos. Segundo Gunther Holbl (2001) a estrutura de poder dos ptolomeus não possuía uma forte característica egípcia nas três primeiras dinastias, entretanto isto não significa a não adoção de práticas mágico-religiosas da monarquia divina egípcia pelos ptolomeus deste período.

Um bom exemplo desta interação é a prática da dinastia ptolomaica em realizar casamentos entre irmãos o que era um estranho elemento à cultura greco-macedônia. Tal prática foi adotada logo no início da dinastia ptolomaica durante o reinado de Ptolomeu II Filadelfo e expresso na estela de Mendes - decreto relativo a cidade de Mendes no Baixo Egito.

É possível que revoltas durante o reinado de Ptolomeu IV e V possam ter favorecido uma a adoção mais significativa da monarquia divina faraônica. De qualquer modo, a legitimidade do poder da dinastia ptolomaica deveria contemplar ambas as culturas e um bom exemplo desta prática religiosa se traduz na preocupação de Ptolomeu I em estabelecer uma divindade como Serápis.

Segundo Plutarco na sua obra "De Iside et Osiride"2 Ptolomeu I teria tido um sonho no qual a estátua de um deus desconhecido aparecia para o monarca. Relatando tal fato aos seus conselheiros verificou-se que a estátua existia na colônia grega de Sinope e logo foi trazida para o Egito.

A narrativa pode ser traduzida como uma revelação divina para o monarca e uma forma de legitimidade diante de segmentos sociais, uma vez que esta divindade deveria possuir elementos da cultura egípcia e grega. Serápis parece não ter dito grande aceitação em solo egípcio, entretanto seu culto foi expressivo no mundo greco-romano.

Segundo a tese de doutorado do professor Lobianco (2006: 237-239) citando o trabalho de Françoise Dunand e Christiane Zivie-Coche (1991:214-216) - este deus tinha se tornado objeto de culto antes da chegada de Alexandre e era conhecido pela população grega de Mênfis na forma de Osor-Hapi. De fato, teria ligação com o touro Apis mumificado.

2 Ver Isis and Osiris. In: Plutarch. Moralia, tome V, transl. Frank Cole Babbitt, Cambridge/Massachusetts/London: Havard University Press, 1936, pp 1-191. 
É possível verificar também em Serápis atributos de Osiris, Apis (deuses egípcios) e Zeus. A iconografia helenizada o representava similar a Zeus tendo Cérbero ao lado. Mas o que nos interessa neste momento é a estratégia realizada pela a dinastia ptolomaica estabelecendo um culto oficial para este deus como uma das fases no processo de legitimidade do poder contemplando assim ambas as culturas - a egípcia e a grega em solo egípcio.

Assim sendo, durante a constituição da dinastia ptolomaica Serápis poderia ser pensado, em um primeiro momento, como um exemplo de hibridismo cultural (ver Bhabha, 2003). Compreendemos este hibridismo como forma de transculturação em zonas de contato de modo a auxiliar no processo de afirmação dessa nova dinastia, sobretudo, no Delta (Norte do Egito) e no Fayum. Apesar de ser uma teoria pós-colonialista parecenos aplicável em momentos específicos da formação da dinastia ptolomaica uma vez que a forte adoção da monarquia divina faraônica na manutenção do poder parece não satisfazer este conceito.

Além da tentativa de estabelecimento de um deus híbrido como Serápis era necessário que o processo de legitimidade do poder da dinastia ptolomaica contemplasse em separado a cultura egípcia e a cultura grecomacedônia. Deste modo, os monarcas se associam por um lado ao panteão egípcio, às práticas mágico-religiosas e aos grupos sacerdotais, sobretudo a escola sacerdotal do deus Ptah de Mênfis. Por outro, estabelecem uma ligação, uma linhagem, a partir de Alexandre.

Em sua passagem pelo Egito, Alexandre viajou vários dias para consultar o oráculo do Oasis de Siwa dedicado a Zeus-Amon e este, por sua fez, o legitimou como herdeiro divino do Egito, provavelmente com base em uma lenda (Hobl, 2001:78) cuja narrativa coloca Alexandre como filho de Olímpia e Nectanebo $\mathrm{II}^{3}$ - último faraó nativo antes da segunda invasão persa.

O fato de Alexandre não ter consultado o oráculo de Tebas - dedicado ao deus Amon-Ra egípcio - pode ser um indício que este oráculo não era capaz de legitima-lo ante a cultura greco-macedônia e a cultura egípcia.

\footnotetext{
${ }^{3}$ Nectanebo II reinou entre 359-342 a.C. sendo derrotado por uma poderosa força persa desaparecendo sem deixar traços.
} 


\section{A legitimidade ptolomaica pela deificação}

Dentre os mecanismos mágico-religiosos que poderiam expressar a legitimidade divina do monarca podemos citar a deificação. Seja em vida ou pós-morte. A deificação em vida foi mais rara no Egito faraônico e pode ser verificada no reinado de quatro monarcas que seguiram por este caminho, ao que parece como parte de um projeto político-religioso. São eles: Hatshepsut (a rainha-faraó), Amenhetep III, Akhenaton e Ramsés II.

Tomemos então como exemplo da deificação Ramsés II, terceiro faraó da $19^{a}$ dinastia 4 , que reinou entre 1290 e 1224 a.C. Ao que tudo indica o projeto empreendido durante seu reinado parece ter sido o mais viável, duradouro e eficaz. Tendo sido o último monarca a estabelecer tal processo. Ou seja, quase sete séculos antes de Ptolomeu I.

Ramsés II parece ter orientado seu projeto político-religioso para estabelecer, em definitivo, a legitimidade da nova dinastia uma vez que não possuía vinculação familiar significativa com $18^{a}$ dinastia. Neste sentido instituiu a capital no Delta, na cidade de Pi-Ramsés que neste momento era o centro do Império. Priorizou as principais escolas sacerdotais (Mênfis, Heliópolis, Hermopolis, Tebas e Elefantina), mas parece ter dado ênfase ao culto de Ra de Heliópolis.

O seu poder era tal que designou como sumo sacerdote de Amon-Ra em Tebas um sacerdote de Ptah da cidade de Mênfis (Kitchen, 1982: 175) reduzindo e mantendo sob o seu controle o poder de Tebas. Defendemos a possibilidade de Ramsés II ter tomado por base a memória de Hatshepsut, Amonhotep III e Akhenaton, na continuidade do projeto político-religioso que o levaria a se legitimar como um deus vivo. O professor Kitchen (1982:174-175) afirma que tal monarca tomou como exemplo por um lado Amonhotep III, faraó que estabeleceu um período de riqueza, paz, desenvolvimento e, tornou-se deus com direito ao culto em vida. Por outro, Akhenaton, cuidando para não proceder como este rei-deus.

A razão de defender a possibilidade que a rainha/faraó Hatshepsut tenha sido levada em conta, reside no fato de que ela foi "o primeiro monarca" conhecido no Reino Novo que desenvolveu culto a sua imagem em vida estabelecendo sua legitimidade através de mitos divinos de concepção e

\footnotetext{
4 A partir de estudos realizados durante o mestrado. Ver (Gralha, 2002 ) Uma nova edição revisada foi publicada em 2017.
} 
nascimento. ${ }^{5}$ De forma similar Amonhotep III inspirou-se nela na adoção de mitos $^{6}$ estabelecendo o culto a sua imagem em vida.

Ela fundiu-se (como assimilação divina) ao deus Amon-Ra na sua iconografia e algo similar foi feito por Ramsés II em relação aos deuses Ra-Harakhty e Amon-Ra. Este monarca parece ter restaurado e utilizado o templo de Hatshepsut, enquanto desmantelava o que ainda existia de Akhet-Aton ou Amarna (Grimal, 1997:261) - capital construída por Akhenaton durante o seu reinado. Ramsés II foi o monarca que usou com maior eficiência a arquitetura, a iconografia e os textos para estabelecer sua legitimidade divina e dinástica.

Mas como isso poderia funcionar no caso ptolomaico durante o período helenizado? Tal prática foi adotada com facilidade? Existia algum tipo de resistência cultural relativa às práticas mágico-religiosas?

Ao que tudo indica, parece não ter existido resistência significativa à adoção de práticas mágico-religiosas egípcias e se aconteceu os indícios são frágeis. Durante o reinado de Ptolomeu I, a construção do Museion (Museu) e da Biblioteca de Alexandria deram aos ptolomeus prestígio diante da cultura grega e contribuíram para a legitimidade do poder real. O que é interessante notar a respeito deste tipo de "Museu" é a prática de um culto.

O Museu é, em sua origem, um lugar sagrado no qual era realizado um culto as musas divinas que presidiam a memória e as atividades do espírito (Husson \& Valbelle, 1992: 195).

A prática do culto ao indivíduo nos século V e IV a.C. não era estranha ao mundo grego sobretudo para os fundadores de cidades. Segundo G. Husson e Dominique Valbele a explicação para o culto real helenístico tem por base uma influência oriental em particular da realeza aquemênida da Pérsia e do culto das cidades gregas dedicados aos seus homens, mortos ou vivos, mas sem considera-los deuses. A esse tipo de culto as egiptólogas denominaram como "o culto real do tipo grego". ${ }^{7}$

Se por um lado isso pode ser visto como um culto real do tipo grego, o mesmo culto possuía elementos similares ao culto ao monarca egípcio, seja na forma do culto em vida, seja na forma do culto em memória ao faraó, que ocorria nos templos com um grupo de sacerdotes específicos. Sendo assim, Ramsés II, por exemplo, era objeto de tal culto no templo de

\footnotetext{
${ }^{5}$ Ver a análise completa no capítulo IV (Gralha, 2002) e (Gralha, 2017).

6 Tais mitos podem ser encontrados no Templo de Luxor.

${ }^{7}$ Le culte royal de type grec.
} 
Abu Simbel na fronteira sul do Egito; Ramsés III, por sua vez, em Medinet Habu na margem esquerda do Nilo (lado contrário da capital Tebas)

A partir do reinado de Ptolomeu II (284-246 a.C.) a expressão divina do monarca parece ter atingido um novo patamar. Logo após a morte de Ptolomeu I, o novo monarca Ptolomeu II "criou um culto em honra ao seu pai morto" o qual Husson e Valbele (1992: 196) denominaram como culto filial. Ao falecer a rainha Berenice I, sua mãe, também foi associada ao culto na forma de um casal divino tratado como deuses salvadores (Theoi Soteres) e parece haver indícios de um templo em Alexandria dedicado ao culto de Berenice por volta de 275 a.C. (Holbl, 2001: 94).

Tal culto tem relação íntima com culto em memória do faraó, comum, sobretudo, no Reino Novo (1550-1070 a.C.) e dada a importância do culto, Ptolomeu II institui a Ptolemaia em Alexandria como uma grande festa em honra ao seu pai, e segundo Husson e Valbele (1992: 196)...

... ele (Ptolomeu II) havia fundado estas festas (Ptolemaia e procissão a Dioniso) em honra de seu pai; sua organização mostra claramente que elas eram destinadas a consolidar o prestígio da dinastia (ptolomaica) diante dos Gregos por que era um agôn isolympios, que concorria em igualdade com os Jogos Olímpicos.

Este culto durante o reinado de Ptolomeu II era tão significativo que pretendia rivalizar com outras atividades do mundo grego e por outro lado adotava práticas mágico-religiosas egípcias. Se Ptolomeu I tentou fortalecer a legitimidade dinástica com o culto de Serápis as práticas promovidas por Ptolomeu II deram continuidade ao projeto políticoreligioso.

A citação abaixo relativa à pesquisa sobre o culto a memória do faraó pode elucidar sobre a função desta prática mágico-religiosa.

\footnotetext{
Recentemente, passou-se a usar o termo memorial temple que poderíamos traduzir como "templo dedicado à memória do monarca", uma vez que "alimentá-lo" não seria a única ação. Ao que parece, havia uma ritualística para manter viva a memória do rei, haja visto que, o monarca era um deus. Assim, o templo, além de possuir ritos funerários e ritualística em memória do monarca, era também o local de culto aos deuses (Gralha, 2002).
}

Além disso, Ptolomeu II estabeleceu também um tipo de culto dinástico na forma do casal real denominado de Theoi Adelphoi (Os deuses irmãoirmã) e os indícios estão no papiro de Hibeh 199 (272/1 a.C.) mesmo antes da morte de Arsinoe II. 
Neste tipo de prática o casal divino era objeto de culto divino em vida, ou seja, deuses vivos. Em certa medida tal prática possuía relações com o culto dinástico ao faraó durante o período faraônico que somente em certos momentos tiveram o estatuto de culto em vida como deuses (não culto à memória).

Deste modo, o culto do tipo filial e do tipo dinástico poderiam ser significativos para estabelecer uma legitimidade mágico-religiosa e dinástica, sobretudo no Delta e no Fayum, e ao que parece não foi suficiente para o Alto Egito de modo a estabelecer um controle dinástico. A expressão da materialidade ainda não era satisfatória para aquela região. Para um estudo amplo do reinado de Ptolomeu II e o culto à Arsinoe II sugiro a dissertação de mestrado "O Culto a Arsinoe II Filadelfo" do professor Alex dos Santos Almeida defendida em 2003 no Museu de Arqueologia e Etnologia da USP.

\section{A legitimidade ptolomaica pela fundação de cidade}

A fundação de uma cidade é outra forma possível de estabelecer legitimidade. Neste caso, a cidade pode passar a capital do reino e (ou) sede da dinastia. Diversos faraós fundaram cidades no processo de legitimação do poder. Akhenaton, por exemplo, em seu projeto políticoreligioso fundou a cidade de Akhet-Aton (Horizonte de Aton) localizada entre Tebas e Heliópolis, e atualmente conhecida como Amarna. Estabelecer a nova capital alterou o eixo de poder de Tebas, em função do culto à Amon-Ra, para Akhetaton, em função do culto ao deus Aton, culto de caráter exclusivamente solar aparentemente associado também à cidade de Heliópolis. ${ }^{8}$

Ramsés II, durante o seu reinado, fundou a cidade de Pi-Ramsés (a casa de Ramsés)não só como de forma a fortalecer o culto solar no Baixo Egito (norte), mas também de estar no centro do Império, o que equivalia a estar entre a Núbia (Sudão) ao sul e regiões próximas ao rio Orontes (Líbano- Síria).

Tendo em vista estes exemplos seria importante para a dinastia ptolomaica a fundação de uma cidade devido o grande impacto que tal prática teria no processo de legitimidade das relações de poder. Como Alexandria e Naukratis - esta última fundada durante a $26^{\mathrm{a}}$ dinastia egípcia (século VII a.C.) tendo população grega em sua maioria estavam consolidadas como cidades helenizadas e uma nova cidade no

8 Ver (Gralha, 2002). O capítulo IV trata desta questão. 
Baixo Egito (no Delta) talvez não tivesse impacto significativo. O Delta era relativamente menor, cosmopolita e provavelmente havia uma maior facilidade de ir de uma cidade a outra cidade. O Alto Egito com certeza seria o grande problema para a administração ptolomaica por ser menos cosmopolita, ter menor densidade populacional e distante do centro de poder. Do ponto de vista sócio-cultural é possível que a helenização ${ }^{9}$ e a egipcianização ${ }^{10}$ tenham sido mais evidentes no Delta.

Desta forma, a fundação da cidade de Ptolemais por Ptolomeu I considerada uma cidade grega - no Alto Egito fazia parte do processo de legitimidade do poder no Sul do Egito e seria a expressão material pública pretendida por este monarca. Entretanto, a característica helenística desta cidade se por um lado favoreceu os segmentos grecomacedônios, por outro lado pode não ter sido satisfatória diante da cultura faraônica, e nesse sentido, não estabeleceu laços fortes com a tradição do Egito faraônico que via em Tebas sua principal cidade na região. $\mathrm{Ou}$ seja, durante este período a monarquia divina do tipo faraônica não estava ainda consolidada pelos reis ptolomaicos, e assim sendo, a legitimidade divina parecia se expressar de forma não satisfatória no que diz respeito à fundação de cidades, sobretudo no Alto Egito.

\section{A legitimidade ptolomaica pela construção de templos}

Um programa de construção de templos parece ser a melhor expressão da materialidade e da legitimidade dinástica ptolomaica devido ao seu valor simbólico, mítico e mágico-religioso, além de promover relações sociais, relações culturais (de certa forma como as cidades) e consolidar relações de poder.

Assim sendo, a fundação de templos significativos ao Sul, a partir do final do reinado de Ptolomeu III, pode ter sido um aspecto significativo da expressão da materialidade e da transcrição pública no processo de legitimidade dinástica; e por sua vez de redução da resistência à dinastia ptolomaica, que havia ocorrido na forma de revoltas como a Rebelião de Tebas (206-186 a.C.) que dividiu as "Duas Terras" - O Alto e Baixo Egito - mais uma vez.

Em função das revoltas (ou não) e das modificações no culto ao monarca nos reinados de Ptolomeu IV e V - principalmente a partir de 206 a.C. -

\footnotetext{
9 Visto como a adoção da cultura grega

10 Visto como a adoção da cultura egípcia
} 
defendemos ser possível que um processo profundo de egipcianização foi levado a efeito tendo como elemento significativo a adoção da monarquia divina cuja expressão da materialidade se traduziria por um programa de construção de templos e adendos na região do Alto Egito, sobretudo, durante os reinados de Ptolomeu IV à VIII em função as complexas relações diante da dinastia ptolomaica.

O que nos interessa é justamente identificar uma das formas encontradas pela dinastia ptolomaica, a partir de Ptolomeu IV, para estabelecer o controle social e político, sobretudo depois da Rebelião Tebana de modo a reforçar a legitimidade do poder ptolomaico no Alto Egito. Provavelmente tropas foram enviadas para esta região e centros administrativos foram organizados principalmente na cidade de Ptolemais, mas isso por si só poderia não ser suficiente para estabelecer o controle da região. Uma legitimidade divina de modo similar à realizada pelos faraós seria necessária como meio não coercitivo de controle. Desta maneira, era preciso se utilizar de práticas mágico-religiosas que já haviam sendo postas em práticas pela dinastia ptolomaica desde Ptolomeu I e a materialização desta legitimidade seria um programa de construções de templos em regiões importantes do Alto Egito.

Ao que tudo indica os três primeiros monarcas não incluíram grandes templos no programa de construções nesta região. Todavia, no reinado de Ptolomeu III um esforço neste sentido foi realizado talvez percebendo a fragilidade do controle social no Sul. Assi sendo, em 237 a.C. teve inicio a construção de um significativo templo - templo Hórus em Edfu -, em parte continuado por Ptolomeu IV. Entretanto, a revolta era eminente e durante tal período os trabalhos foram paralisados.

De Ptolomeu IV a Ptolomeu VIII em maior medida este programa de construção levou a realização de obras ou adendos aos mais importantes templos da região que levaram dezenas e dezenas de anos para serem completados: nos referimos ao templo de Hathor em Dendera, ao templo de Hórus em Edfu, ao templo de Knum em Esna, ao templo de Hórus e Sobek em Kom Ombo, ao templo de Isis em Filae e ao templo de Hórus em Kalabsha (perto de Elefantina) tendo como faraó Augusto. Este último erigido na transição entre a dinastia ptolomaica e a ocupação romana. 


\section{A Legitimidade ptolomaica pela titulatura faraônica}

Parece oportuno utilizar o trabalho realizado por nós na dissertação de mestrado sobre a titulatura faraônica ${ }^{11}$ de forma a demonstrar a legitimidade da titulatura ptolomaica uma vez que o nome ou denominação de algo era de grande importância na materialidade de processos mágico-religiosos. Assim sendo, tomaremos a definição de magia e ação mágica de Richard Wilkinson (1994) cujo enunciando demonstra, que na crença egípcia descrever ou escrever uma dada situação, em um processo ritual, poderia fazer tal ação se tornar real. $\mathrm{O}$ que significa dizer que a titulatura e os epítetos carregavam um significado mágico-religioso que poderia ser aplicado ao mundo real.

Neste sentido, a criação de uma titulatura e de epítetos para o faraó poderia mostrar as características e atributos divinos do futuro monarca, seu "programa de governo", e reafirmar a natureza dual do rei (humano e divino) e sua relação com o deus. A titulatura passa então a constituir um conjunto de palavras que possuíam poder e por práticas mágicas poderiam expressar a materialidade das ações do faraó, ora como ser humano ora como ser divino, fazendo menção ao aspecto da natureza dual do rei.

No estudo sobre os dois corpos do rei (natureza dual do monarca), desenvolvido pelo egiptólogo Siegfried Morenz (1996:37) o epíteto hem e o epíteto niswt podem ser tomados como exemplo: hem - "sua majestade" que Siegfried afirma ser originalmente a palavra "corpo" e outros egiptólogos definem como "escravo ou servo" - estaria ligado à natureza humana da pessoa que exerce a função real. Segundo Silverman (1991: 67) estaria relacionado à incorporação viva do rei ("living embodiment of the $k i n g ")$, ou seja, à pessoa do faraó, e era a forma pela qual o rei era descrito por outros (como nas biografias) ou por si próprio. Quanto ao termo niswt (uma outra formar de definir "rei") representaria as funções e atributos do monarca em um sentido divino.

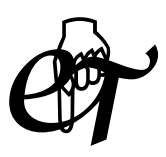

$h m$

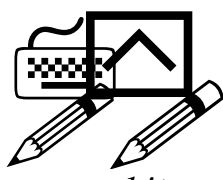

nsw bity

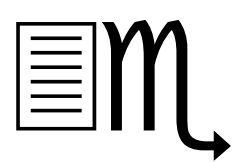

$n$ tr $n f r$

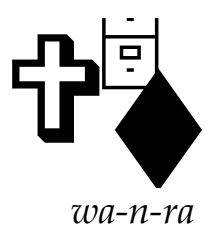

Fig. 1. Epítetos e elementos da titulatura do rei

11 Defendida em 2000, publicada em 2002 e edição revisada em 2017. 
O elemento da titulatura (nsw bity) - "Rei do Alto e Baixo Egito" - estaria ligado ao caráter divino do faraó, sendo normalmente empregado em decretos legais, administrativos, econômicos, nos templos e nas inscrições funerárias. Além destes, um outro epíteto, netjer nefer ( $n$ tr $n f r$ ) - "Bom deus" ou "deus perfeito" - tinha igual importância nas descrições e ações administrativas, reais e relativas ao templo, e enfatizava o caráter divino do monarca.

A titulatura oficial do monarca era composta de cinco títulos, sobretudo a partir do Reino Médio (2040 - 1640 a.C.). A maior parte destes cinco títulos parece ter sido desenvolvida durante o Reino Antigo (2575-2134 a.C.) e o Primeiro Período Intermediário (2134-2040 a.C.).

Com relação aos epítetos, eles foram encontrados em todos os períodos e variavam dependendo do momento. Passamos a descrever os cinco títulos, que compunham a titulatura básica oficial do rei com base nas definições propostas pela Egiptologia (Boheme, BIFAO 78, 1978: 347; Boheme e Forgeau, 1988: 36-40 e Allen, 2004: 64-65).
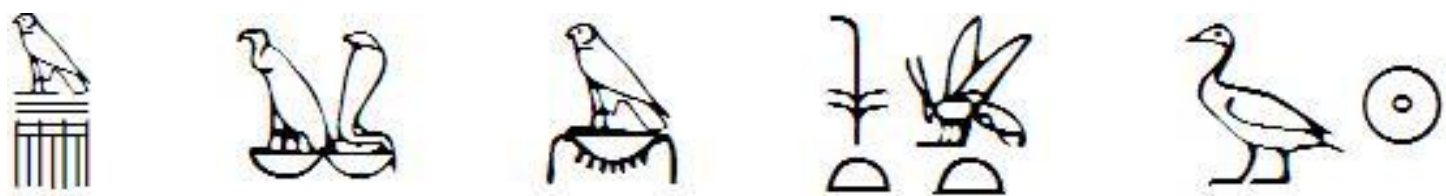

Fig. 2. Titulatura do rei

A descrição a seguir está da esquerda para direita:

HÓRUS - Este título pode ser encontrado nos primeiros monarcas do Período Arcaico (2920-2575 a.C.). O nome do faraó era inscrito um retângulo que de fato representava uma grande sala com colunas que poderia ser o palácio do monarca. Como o faraó era identificado com o deus Hórus este estava desenhado sobre a sala ou retângulo demonstrando a proteção e supremacia desta divindade. Este Hórus não é o filho de Isis e Osíris, mas o Hórus o "deus do céu". Este conjunto tinha o nome de Serekh e significava segundo o estudo de Marie-Ange Bonhême e Annie Forgeau "fazer saber ou proclamar". Provavelmente, a habilidade de voar muito alto e em direção à luz solar pode ter gerado esta representação de Hórus e a associação com o monarca.

AS DUAS DAMAS (nbty) - Uma das hipóteses é significa as duas terras do Egito. O Sul, o Alto Egito, seria identificado pela deusa abutre Nekhabit e o Delta (o Norte), pela deusa serpente Uadjit ou Uto, esta aparecendo atrás do abutre, uma visão clara da vitória do Sul sobre o 
Norte durante a unificação do Egito. Uma outra relação pode ser verificada: como o Delta é mais úmido e possui mais vegetação, o que pode ter facilitado a proliferação de serpentes, esta teria se tornado o emblema desta região.

HÓRUS DE OURO ou FALCÃO DOURADO - Este título parece estar associado ao mito de Osíris, à luta mítica de Hórus e Seth, e ao culto solar, provavelmente incorporado no Reino Antigo durante a primazia de Ra.

REI DO ALTO E BAIXO EGITO - Acompanhava o nome de coroação (nome do trono) do monarca e teria relação com o culto solar. Demonstrava a dualidade do Egito e da instituição da teocracia faraônica.

FILHO DE RA - Passou a acompanhar o nome de nascimento do monarca a partir da $5^{\text {a }}$ dinastia, tornando-se regular na titulatura. Indicava que o monarca era divino por nascimento e possuía caráter solar.

Os três primeiros títulos podiam denotar as características da natureza dual do monarca. O Hórus de Ouro é um bom exemplo. Este Hórus fazia parte do mito de Osíris, levando o falecido, no rito funerário, diante deste deus depois da pesagem do coração. Também aparece na Enéada de Heliópolis tendo ligação com o culto solar, dessa forma assumindo o poder divino e dual de Ra e Osíris.

Por outro lado, era também identificado com o monarca que assumia o trono do Egito. Os outros dois títulos, de coroação e nascimento (provavelmente os mais importantes), poderiam indicar a natureza dual do monarca, ambas "solarizadas": a primeira, a natureza institucional da teocracia faraônica; a outra, a natureza divina do faraó, uma vez que ele era o "filho de Ra".

Este conjunto de títulos e epítetos poderia ratificar o caráter divino do monarca e sua ação como governante do Egito. Poderia representar também, de uma forma geral, um "programa de governo". Alguns exemplos podem elucidar tais questões.

Quando Akhenaton iniciou sua "revolução" foi necessário expressa-la na sua titulatura. Desta forma substituiu o deus Amon pelo deus Aton. Além disso, o maior exemplo de mudança radical teria sido a substituição total do seu nome de nascimento de Amonhotep - "Amon é gracioso" - para Akhenaton, que pode ser traduzido como "Alma de Aton", "Radiação de Aton", "Aquele que é útil para Aton" (Hournung, 1999: 50). Ele também criou um novo epíteto Ua-en-Ra "O primeiro de Ra". A titulatura completa era a expressão da materialidade que deveria ser usada nas 
transcrições públicas. Um outro exemplo do uso da titulatura como forma de legitimidade de ações pode ser encontrada na dinastia raméssida.

Ramsés I, fundador da $19^{a}$ dinastia, não possuía sangue real; vinha de uma linhagem de soldados do Delta e parece ter sido vizir durante o reinado de Horemheb. Segundo Pierre Grimal (1997: 245-246) sua titulatura poderia ser lida da seguinte forma:

Seu nome de Hórus de Ouro seria "Aquele que confirma Maat nas Duas Terras", indicando a sua continuidade com o trabalho de Horemheb, reestruturando o Egito após o Período Amarniano, mesmo não tendo qualquer relação com a dinastia anterior. Afinal isto criaria legitimidade.

O nome das Duas Damas, "Aquele que foi coroado rei, escolhido por Atum"; o significaria que para governar as Duas Terras do Egito o deus Atum (mito solar de Heliópolis), aquele que deu início a criação, foi quem escolheu este monarca.

O nome de Coroação (nome de trono) Menpehtyra, "Estável é o poder de $\mathrm{Ra}^{\prime}$; e o nome de nascimento, Ramessu, "Ra o gerou", demonstram uma aproximação com o Baixo Egito, sobretudo Heliópolis, centro do culto solar, tendo sua legitimidade real sido expressa evocando Atum e Ra.

Neste ponto defendemos que a dinastia ptolomaica também fez uso desta prática mágico-religiosa no projeto político-religioso de legitimidade dinástica se utilizando da titulatura associada a epítetos gregos. É possível perceber certa sofisticação na titulatura ptolomaica durante os reinados de Ptolomeu IV e V momento em que tais monarcas parecem intensificar a adoção de práticas relativas a monarquia divina egípcia possivelmente em função das rebeliões no Egito. A análise da titulatura ptolomaica pode contribuir para o estudo da legitimidade do poder desta dinastia. Passamos então a usar a técnica de análise dos conteúdos apresentada por André D. Robert e Annick Boulillaguet no livro L'Analyse de Contenu.

Será utilizado um quadro de análise simplificado de modo a tornar mais claro a aplicação do método, entretanto descreveremos todas as possibilidades do método.

Segundo os autores a análise dos conteúdos stricto sensu se define como uma técnica, que permite o exame metódico, sistemático, objetivo e, dependendo da ocasião, quantitativo dos conteúdos de certos textos visando classificar e interpretar seus elementos constitutivos os quais não são totalmente acessíveis a uma leitura ingênua (Robert e Bouilaguet, 
1997: 4). Tomamos por base que TEXTO significa aqui todo tipo de produção verbal, escrita ou oral. Além disso, concebemos como texto a iconografia e a arquitetura quando estas podem ser lidas e interpretadas.

A partir de quatro etapas básicas, ou seja: 1) A análise prévia que visa definir um corpus documental com base nos textos disponíveis; 2) a categorização distinguindo-se temas ou categorias temáticas, que de um modo geral, permitam comparações significativas aos diferentes textos que integram o corpus; 3) a delimitação das unidades que determinarão os recortes. De um modo geral as unidades se classificam em registro, de numeração e de contexto e finalmente 4) a análise qualitativa dos conteúdos.

A partir destes quatro elementos centrais da Análise dos Conteúdos foi possível criar um quadro de análise simplificado que pode ser usado para análise de textos e imagens. A numeração dos títulos que se encontra nos quadros reflete de forma concisa as quatro etapas do método. Além disso, foram tomados para a análise dois dos cinco títulos possíveis: o nome de coroação/trono e o nome de nascimento (os mais claramente observados nos textos), e de certa forma, os mais importantes no processo mágico-religioso além de manter uma homogeneidade do corpus tendo vista que nem todos os títulos foram reconstituídos. Neste artigo tomamos como exemplo somente a titutlatura de Ptolomeu V que denota aparentemente uma maior aproximação com cultura faraônica, mas também demonstra inovações significativas tendo em vista que a titulatura possui epítetos gregos transcritos para o egípcio antigo.

\section{Quadro da Análise dos Conteúdos: Titulatura de Ptolomeu V}

\begin{tabular}{|c|c|c|}
\hline \multicolumn{3}{|c|}{ Titulatura de Ptolomeu V Epifanes (210-204-180 a.C.) } \\
\hline \multicolumn{3}{|c|}{ Bibliografia (1) } \\
\hline \multicolumn{3}{|c|}{ Liddell and Scott's (1997), Holbl (2000), Gralha(2002), Chauvau (1997), www.narmer.pl } \\
\hline Texto(1) & \multicolumn{2}{|c|}{ Observação } \\
\hline $\begin{array}{l}\text { Nome de coroação e } \\
\text { nascimento do faraó }\end{array}$ & \multicolumn{2}{|c|}{$\begin{array}{l}\text { Análise parcial da titulatura: nome de coroação/trono e nome } \\
\text { de nascimento de Ptolomeu V Epifanes }\end{array}$} \\
\hline \multicolumn{3}{|c|}{$\begin{array}{l}\text { Categoria Temática (2): Legitimidade divina na titulatura } \\
\text { Análise parcial da titulatura: nome de coroação/trono e nome de nascimento }\end{array}$} \\
\hline \multicolumn{2}{|c|}{$\begin{array}{l}\text { Unidade de Registro (3) } \\
\text { Nome de coroação ou trono } \\
\text { Rei do Alto e Baixo Egito }\end{array}$} & Análise qualitativa do conteúdo (4) \\
\hline 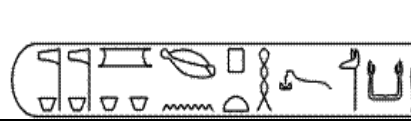 & & .O termo "carne e osso" \\
\hline
\end{tabular}




\begin{tabular}{|l|l|}
\hline \multicolumn{1}{|c|}{$\begin{array}{l}\text { iwa-n-nTrwi-mr(wi)-it stp.n- } \\
\text { ptH wsr-kA-ra sxm-anx-n-imn }\end{array}$} & também como herdeiro. \\
$\begin{array}{l}\text { Carne e osso amado dos dois pais } \\
\text { divinos, o escolhido de Ptah o } \\
\text { poderoso ka de Ra e o poder (de } \\
\text { ação) em vida de Amon. }\end{array}$ & "O amado dos dois pais divinos" \\
& $\begin{array}{l}\text { O epíteto se refere aos pais (Ptolomeu IV e Arsinoe } \\
\text { III) de Ptolomeu V e de fato tem relação com a } \\
\text { transcrição do epíteto Filopator. } \\
\text { Ptah, Ra e Amon compõem o nome de coroação como } \\
\text { legitimidade divina seguindo a política do pai. } \\
\text { “O escolhido de Ptah" no nome de coroação/trono } \\
\text { denota uma ligação com o segmento sacerdotal de } \\
\text { Mênfis. } \\
\text { O monarca é o escolhido de Ra forma de legitimidade } \\
\text { via o deus solar do Baixo Egito (norte) através de } \\
\text { Heliópolis. } \\
\text { O monarca tem o poder (de ações) em vida de Amon } \\
\text { o que denota ser o poder encarnando deste deus. Uma } \\
\text { tentativa de legitimidade via o deus de Tebas }- \text { a } \\
\text { capital do Alto Egito. }\end{array}$ \\
\hline
\end{tabular}

\begin{tabular}{|l|l|}
\hline $\begin{array}{l}\text { Unidade de Registro (3) } \\
\text { Nome de Nascimento - Filho } \\
\text { de Ra }\end{array}$ & Análise qualitativa do conteúdo (4) \\
\hline $\begin{array}{l}\text { Ptwlmis anx-D tmri-ptH } \\
\text { de Ptahe viva para sempre, amado }\end{array}$ & $\begin{array}{l}\text { O nome de nascimento está egipcianizado e possui } \\
\text { ligação com o deus Ptah o que denota forte } \\
\text { aproximação com o grupo sacerdotal de Mênfis. }\end{array}$ \\
\hline $\begin{array}{l}\text { Unidade de Registro (3)Epíteto } \\
\text { Grego }\end{array}$ & $\begin{array}{l}\text { Análise qualitativa do conteúdo (4) } \\
\text { Epifanes }\end{array}$ \\
$\begin{array}{l}\text { Manifestação, aparição divina. (LIDDELL AND } \\
\text { O epíteto demonstra o caráter divino e manifesto do } \\
\text { novo monarca. Considerado divino tanto pelo epíteto } \\
\text { grego quanto pela titulatura faraônica. }\end{array}$ \\
$\begin{array}{l}\text { Ptolomeu V estabelece legitimidade divina diante da } \\
\text { sociedade egípcia e dos faraós do Alto Egito. }\end{array}$ \\
\hline
\end{tabular}




\section{Considerações Finais}

Neste artigo, que é parte dos estudos realizados no mestrado e no doutorado, nossa intenção foi demonstrar que a dinastia ptolomaica, para se legitimar no poder por quase três séculos, precisou adotar práticas mágico-religiosas faraônicas. Assim sendo, de forma concisa abordamos quatro possibilidades: a legitimidade pela deificação, pela construção de cidade, pela construção de templos e pela titutlatura.

Elemento significativo neste processo se refere a egipcianização da dinastia ptolomaica que pode ter sido muito mais importante para a manutenção e legitimidade nas relações de poder do que a helenização proposta pela historiografia.

Tratar o Egito deste período como um "Egito helenizado" somente pode significar uma redução de análise em face à complexidade deste momento e pode não elucidar as estratégias e as práticas adotadas pelos monarcas desta dinastia. Outrossim, a historiografia costuma colocar a dinastia ptolomaica como algo a parte. É preciso salientar que estes reis passaram pelos ritos faraônicos, nasceram em solo egípcio, adotaram em parte a cultura egípcia e governaram o Egito "no próprio Egito". Ou seja, são faraós e não somente reis ptolomaicos.

\section{Bibliografia}

AUSTIN, M. The Hellenistic World from Alexander to the Roman Conquest: A Selection of Ancient Sources in Translation. Cambridge: Cambridge University Press, 1981.

COPPENS, Fillip. The Wabet: Tradition and Innovation in Temples of the Ptolemaic and Roman Period. Praga: Czech Institute of Egyptology, 2008.

BAGNALL, R \& DEROW, Peter. The Hellenistic Period: Historical Sources in Translation. Nova York, Blackwell Publishing, 2004.

BELL, Lanny. The New Kingdom “Divine" Temple: The example of Luxor. In: SHAFER, Byron E. (Editor). Temples In Ancient Egypt. New York: Cornell University Press. 1999.

BHABHA, Homi K. O Local da Cultura. Belo Horizonte: Editora UFMG, 2003.

BOWNMAN, Alan K. Egypt after the Pharaohs 332BC-AD642. London: British Museum Publications, 1986. 
DUNAND, Françoise. Diex et Hommes en Egypte. 3000 av. J.C. - 395 apr. J.C. Paris: Armand Colin, 1991, pp 214-216.

FLANNERY, Kent V and MARCUS, Joyce. Cognitive Archaeology. In: HODDER, Ian and

FRANKFURTER, David. Religion in Roman Egypt: Assimilation and Resistance. Princenton: Princenton University Press, 1998.

FUNARI, Pedro P, ZARANKIN, A. Algunas consideraciones arqueológicas sobre a vivienda doméstica en Pompeya. Gerion, Buenos Aires, No 19 pp. 493$511,2001$.

FUNARI, Pedro P., HALL, Martin, JONES, Siân. Historical Archaeology. Back from the edge. London: Routledge, 1999.

GOHARY, Jocelyn. Akhenaten's Sed-Festival at Karnak. London: Kegan Paul International. 1992.

GRALHA, Julio. Deuses, Faraós e o Poder. Rio de Janeiro: Barroso, 2002.

. A Cultura Material do Cotidiano: Espaço Urbano e Moradias no Egito Faraônico. In: Funari, P.P.A.; Fogolari, E. P. (eds.) Estudos de Arqueologia Histórica. 1 ed. Habitus, Erichin (RS), pp. 115-132, 2005.

Arquitetura e iconografia templária: abordagem possível das práticas culturais e da legitimidade do poder no Egito Greco-Romano, Curitiba: 2005, vol 6, 49-68.

. Power and Solar Cult in Ancient Egypt: An Iconographic and PoliticReligious approach. In: Funari, P.P.A.; Garraffoni, R. S.; Letalien, B. (eds). New perspectives on the Ancient World. Oxford: Archaeopress, 2008, pp. 167-174.

. A Legitimidade do Poder no Egito Ptolomaico: cultura material e práticas mágico-religiosas, Campinas (Brasil). UNICAMP, 2009.

GRIMAL, Nicolas. A History of Ancient Egypt. Oxford: Blackwell, 1997.

HAENY, Gehard. A Short Architectural History of Philae. In: BIFAO.

CAIRO: IFAO, volume 85, 1985, pp. 197-233.

HEINEN, H. The Syrian-Egyptian Wars and the new kingdom in Asia Minor. In: WALBANK. F. W. Cambride Ancient History - Hellenistic World. Cambridge: Cambridge University Press, 1984. 
HOBL, Gunther. A History of the Ptolemanic Empire. London: Routledge, 2001.

HORNUNG, Erik. Conceptions of God in Ancient Egypt. The One and the Many. Ithaca (NY): Cornell University Press, 1996.

HORNUNG, Erik. Akhenaten and the Religion of Light. New York: Cornell University Press, 1999.

HUSSON, Geneviève \& VALBELLE, Dominique. L'État et les Institutions en Égypte des premiers pharaons aux empereurs romains. Paris: Armand Colin, 1992.

JOHNSON, Janet. The Demotic Chronicle as a statement of Theory of Kingship. The SSEA Jornual. Toronto, Canada, vol XIII, No 2, spring 1983 . The Demotic Chronicle as Historical Source. ENCHORIA, Zeitschrift Fur Demostistik und Kptologie, IV, 1974.

JOUGUET. Pierre. La Politique intérieure du premier Ptolémée. in: BIFAO. CAIRO: IFAO, volume 30, 1930, p. 513-536.

KITCHEN, K. A. Pharaoh Triumphant The Life and Times of Ramesses II. Wiltshire: Aris \& Phillips LTD., 1982.

LEWIS, Naphtali. Greeks in Ptolemaic Egypt.Oakville-Connecticut: American Society of Papyrologists, 2001 (1986 1 ${ }^{\mathrm{a}}$ ed.).

. Life under Roman Rule. Oxford:Claredon Press, 1985.

LOBIANCO, Luís E. A Romanização no Egito: Direito e Religião (séculos I à III d.C.). Niteroi:UFF, 2006.

MESKELL, Lynn. Archaeologies of Social Life. Oxford: Blackwell, 1999

W.M. Müller, Egyptological Researches III. The bilingual decrees of Philae (Washington 1920), pp. 59-88.

MORENZ, Siegfried. Egyptian Religion. New York: Cornell University Press, 1996.

PINCH, Geraldine. Magic in Ancient Egypt. Austin: Universidade do Texas, 1994

P.W. Pestman, J. Quaegebeur, R. L. Vos, Recueil de textes démotiques et bilingues (Leiden: 1977): 11. 
QUIRKE, Stephen. Ancient Egyptian Religion. London: British Museum Press, 1994.

. The Cult of Ra. Sun-worship in Ancient Egypt. London: Thames \& Hudson, 2001.

ROBINS, Gay. The Art of Ancient Egypt. Cambridge (Massachusetts): Harvard University Press 1997.

- Women In Acient Egypt. Cambrige (Massachusetts): Harvard University. Press, 1993.

ROBERTSON D. S. Arquitetura Grega e Romana. São Paulo: Martins Fontes, 1997.

SAUNERON, S. The Priests of Ancient Egypt. Ithaca: Cornell University press, 2000.

SADEK, Ashraf Iskander. Popular religion in Egypt during the New Kingdom. Hildesheim:Gersten-berg Verlag, 1987.

SCOTT, James C. Domination and the Art of Resistance: Hidden Transcripts. New Haven: Yale University, 1999.

SHAFER, Byron E. (Editor). Temples In Ancient Egypt. New York: Cornell University Press, 1999.

. (Editor). Religion in Ancient Egypt. Gods, Myths, and Personal Practice. New York: Cornell University Press, 1999.

SILVERMAN, David P. Divinity and Deities in Ancient Egypt, in Religion, in Ancient Egypt. SHAFER, Byron (Editor), London: Cornoell University Press, 1991.

TRIGGER, Bruce G. Early Civilizations. Ancient Egypt in Context. Cairo: The American University in Cairo Press, 1996.

VALBELLE, Dominique. Histoire de l'État pharaonique. Paris: Presses Universitaire de France, 1998.

WATTERSON, Barbara. The House of Horus at Edfu. Ritual in an Ancient Egyptian Temple. Great Britain: Tempus, 1998

WILKINSON, Richard H. The Complete Temples of Ancient Egypt .London: Thames \& Hudson, 2000. 
Reading Egyptian Art : A Hieroglyphic Guide to Ancient Egyptian Painting and Sculpture.London: Thames \& Hudson, 1996.

WHINTER, Frederick. Studies in Hellenistic architecture .Toronto: Toronto University Press, 2006. 